5 eventos 


\title{
BIO-STRUCTURAL ANALOGIES: ARMS, WINGS AND MECHANICAL THINGS (WORKSHOP E EXPOSIÇÃO)
}

\author{
DESIGN PROCESS (PALESTRA)
}

\author{
Clice de Toledo Sanjar Mazzilli \\ Cibele Haddad Taralli \\ Artur Simões Rozestraten
}

\section{O CONTEXTO}

Em fevereiro de 2012, recebemos, na FAUUSP, o professor Anthony Viscardi, titular da Lehigh University (EUA), Department of Art, Achitecture, and Design, que conduziu o workshop "Bio-structural analogies: arms, wings and mechanical things". O primeiro contato com o professor deu-se no evento XIII Generative Art International Conference, em dezembro de 2010, no Politécnico di Milano, Itália, onde ele apresentou o trabalho With drawing: to see if you see what you see, com uma abordagem destacada do desenho como processo gerativo de pensar a arquitetura e o design. A afinidade com as questões do processo criativo em projeto, envolvendo, simultaneamente, procedimentos da arte, do design e da tecnologia gerativa, aproximou nossos interesses acadêmicos e motivou a busca de possíveis intercâmbios entre nossas instituições.

Nesse sentido, uma primeira visita do professor Viscardi à Escola ocorreu em maio de 2011, por um período de sete dias, com o apoio da Pró-Reitoria de PósGraduação da USP. Ele veio participar da disciplina de pós-graduação AUP5896 Seminários de Pesquisa em Design e Arquitetura, que, na ocasião, discutia as abordagens teórico-metodológicas e a reformulação de suas linhas de pesquisa. Em 19 de maio de 2011, proferiu a palestra "Processo criativo de projeto", aos alunos de pós-graduação, e realizou atendimentos para casos específicos de mestrado e doutorado. Viscardi proferiu outras duas palestras para os alunos de graduação, sendo uma na disciplina AUP608 - Fundamentos de Projeto, do curso de Arquitetura e Urbanismo, e outra para os alunos do curso noturno de Design, aberta à comunidade. Suas apresentações versaram sobre as pesquisas que desenvolve no campo do ensino de projeto, abordando questões do processo criativo em diferentes níveis de complexidade - considerando a interação entre atividades manuais e digitais, articulando o desenho de observação, desenhos analíticos e projetuais, conceitos de simulacro e analogia, procedimentos de modulação e repetição, estruturas e sistemas estáticos, articulados ou cinéticos, confecção de modelos tridimensionais e fabricação digital. Expôs também sua pesquisa artística atual, intitulada Shadow mapping, e seus possíveis desdobramentos no processo de projeto.

Além das palestras, e com o intuito de programar atividades futuras, realizamos um encontro do professor Viscardi com professores e pesquisadores do Laboratório de Design Visual (LabVisual), do Laboratório de Design do Produto do Ambiente Construído (LabDesign), do Laboratório de Modelos e Ensaios (Lame) e com 
professores dos departamentos de Projeto e de Tecnologia da FAUUSP. Dessa reunião, surgiu a proposta de realização de um workshop imersivo, no primeiro semestre de 2012, durante as férias de verão, com a perspectiva de intercâmbio entre alunos de graduação, iniciação científica, além de professores e pesquisadores da pós-graduação. Esse possibilitaria o aprofundamento das questões levantadas, com efetiva prática de ensino e pesquisa experimental, colaborando fortemente com algumas investigações em curso sobre processos de projeto. Dentre as abordagens expostas pelo professor Viscardi, tivemos especial interesse pelo estúdio intitulado Bio-structural analogies: arms, wings and mechanical things, por seu caráter investigativo do funcionamento de elementos da natureza, dos mecanismos, dos detalhes, gerando o pensamento sistêmico - tão caro para o design e a arquitetura. Por outro lado, interessavam-nos, também, os procedimentos que, por princípios de "simulação" e "analogia", incluíam fortemente o desenho e os modelos tridimensionais, como protagonistas do pensamento projetual.

Considerando esse contexto, planejamos a vinda do professor Anthony Viscardi para o período de 6 a 27 de fevereiro de 2012, contando com o apoio da PróReitoria de Pós-Graduação da USP, da Diretoria da FAU e da Comissão de PósGraduação da FAUUSP. O projeto foi também uma ação conjunta dos laboratórios LabVisual, LabDesign e Lame, coordenado e organizado pelos professores Clice de Toledo Sanjar Mazzilli, Cibele Haddad Taralli e Artur Simões Rozestraten. Foram previstas três etapas de trabalho:

Etapa 1: Período preparatório do workshop. Encontros do professor com a comissão organizadora, para verificação dos ambientes de trabalho, dos materiais e de todas as condições preliminares exigidas para o bom desenvolvimento das atividades.

Etapa 2: Desenvolvimento do workshop. Sete dias intensivos de trabalho, em período integral, nos espaços do Estúdio 1, sala de aula e Lame.

Etapa 3: Avaliação e síntese do workshop: organização de exposição dos trabalhos desenvolvidos (Salão Caramelo), reunião e debate com professores, pesquisadores e alunos, e palestra e exposição na Sala dos Espelhos ( FAUMaranhão).

Para a realização das atividades, foi necessária a configuração de espaços de trabalho para facilitar a interação entre desenho (manual e eletrônico) e modelagem, com materiais diversos, utilizando a máquina de corte a laser e demais recursos técnicos presentes no Lame. Para tanto, foram realizadas reuniões com a equipe desse laboratório, para preparação das atividades, compra de materiais e organização de recursos humanos e de infraestrutura para o apoio didático, contando-se com o auxílio permanente de seus funcionários, para orientação técnica e execução dos modelos. De outra parte, contou-se também com o apoio do Laboratório de Programação Gráfica (LPG), para impressão de folders, certificados, desenhos digitais, montagem dos cartazes finais, impressões e plotagens de trabalho; e dos Laboratórios de Fotografia e de Vídeo da FAUUSP, para registro constante das atividades, gerando um amplo arquivo de documentos e bases visuais, para reflexões teórico-críticas posteriores, a serem difundidas em publicações futuras.

Dada a característica imersiva e experimental do workshop, o número de participantes foi limitado a 15, entre alunos de graduação ou pós-graduação da 

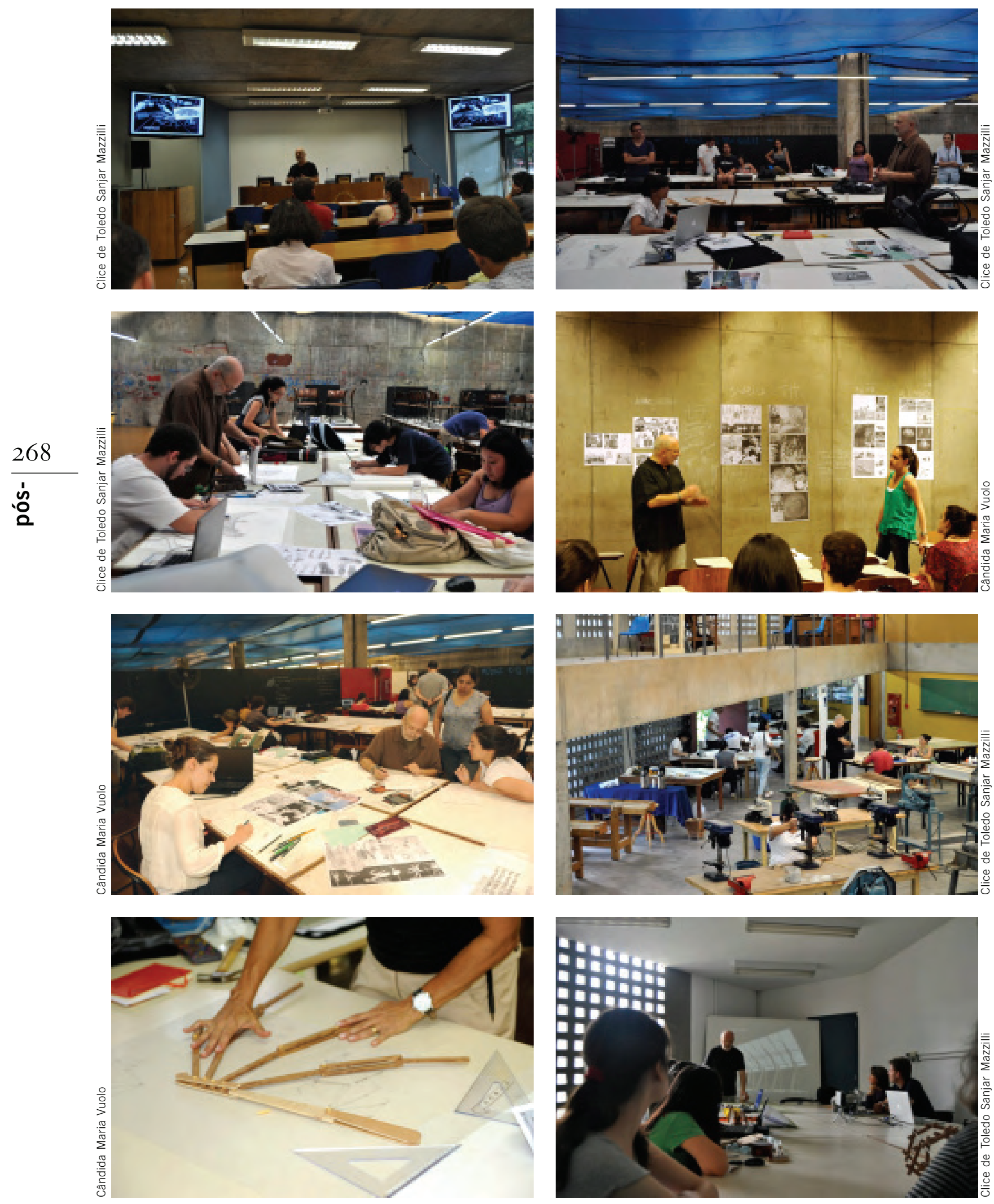

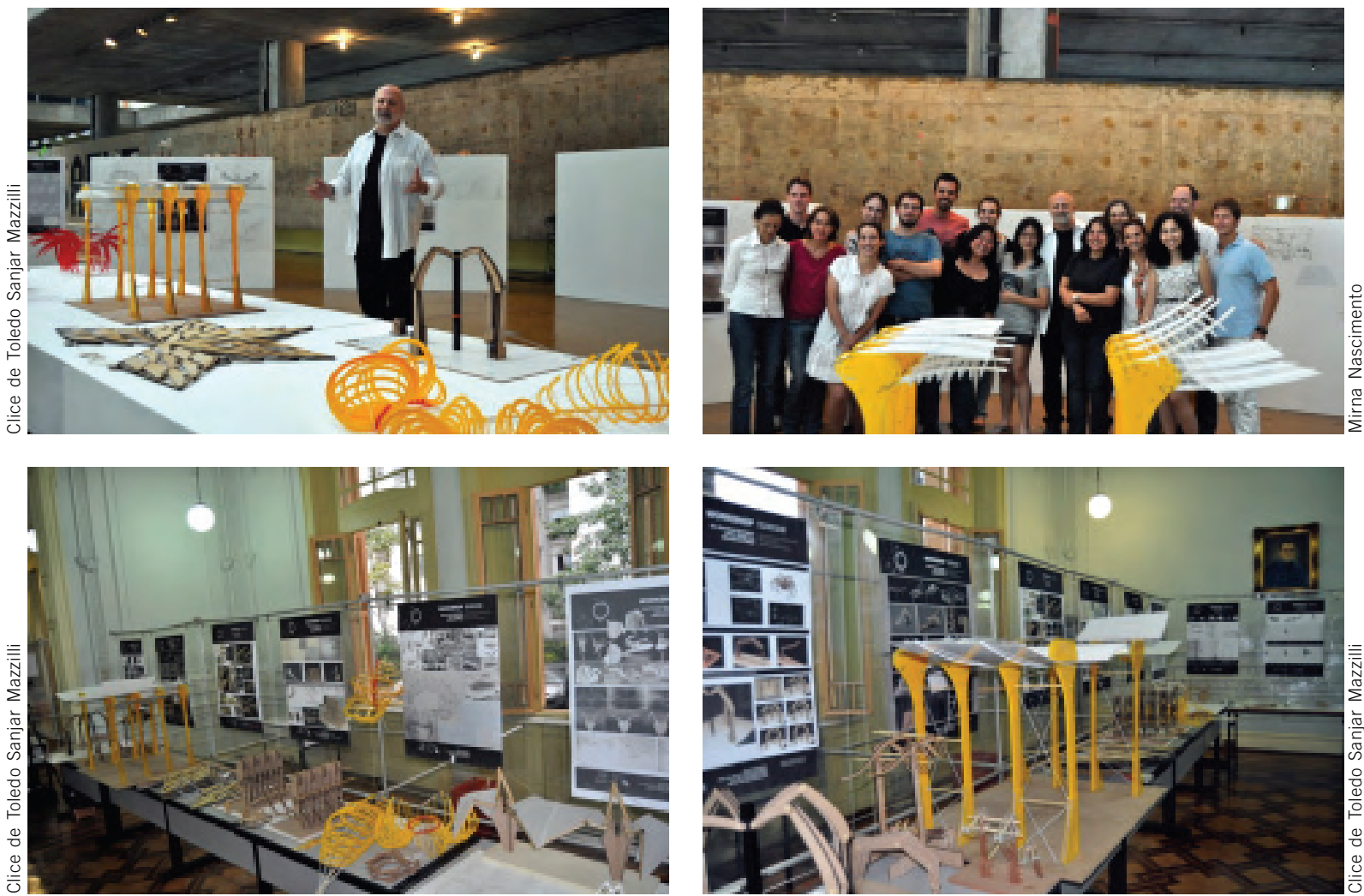

pós-

FAUUSP, pelo mérito acadêmico e interesse no tipo de abordagem proposto. Contamos com a participação de nove alunos de graduação e seis alunos de pósgraduação. Os alunos de graduação participantes: Alexandre Lins do Santos, Beatriz Figueiredo Andrade Brito (IC - bolsista Fupam), Fernanda Gebaili Basile Carlovich, Giulia Calistro, Miguel Falci Câmara (IC - Bolsista Fapesp), Rodrigo Coelho Cavalcante, Tania Mayumi Senaga (estagiária USP - Lame), Vinicius Langer Greter e Yeni Li (IC - bolsista Ensinar com Pesquisa). Os alunos de pósgraduação: Alessio Perticarati Dionisi (IPT), Anamaria Amaral Rezende Galeotti, Elizabeth Romani, Isabela Paiva Gomes Ferrante, Giulia Bettini Calistro, Miriam Andraus Papallardo e Silvia Lenyra Meirelles Campos Titotto.

\section{O WORKSHOP}

O workshop Bio-structural analogies: arms, wings and mechanical things, como indica o título, teve como conceito/problema as "analogias bio-estruturais" como provocadoras do processo de projeto, buscando desenvolver objetos arquitetônicos cinéticos, flexíveis e articulados como sistemas. Os procedimentos tiveram como base os princípios de simulacro e analogia, utilizando como estímulo as aproximações comparativas entre asas, braços e máquinas com articulações e movimentos semelhantes. O grande desafio colocado foi perceber que a observação atenta do detalhe, com foco de interesse em uma determinada articulação, ou tipo/característica de movimento, pode gerar, por multiplicação das partes, estruturas complexas e dinâmicas derivadas da natureza, compondo formas alternativas de proposições arquitetônicas. O caminho projetual proposto 
desliza a partir do desenho como observação, expressão e compreensão de fenômenos naturais, físicos e relacionais (entre si e com outras estruturas mentais), passando pela geometrização formal e estrutural, e evoluindo para a modelagem proporcionada pelos recursos materiais e tecnológicos, percurso esse gerador de elementos participantes do processo criativo.

A atividade de abertura do workshop foi uma palestra proferida pelo professor Viscardi, aos alunos e professores participantes, na terça-feira, 7 de fevereiro, às 17 horas, na Sala da Congregação da FAU. Nessa oportunidade, além das apresentações iniciais, foram expostas as referências conceituais que balizam a proposta, assim como exemplos de trabalhos realizados em experiências anteriores, já conduzidas pelo professor em outras faculdades de arquitetura e design, na Malásia, Finlândia, Alemanha e Itália.

Durante a manhã da quarta-feira, dia 8 de fevereiro, cada aluno, por meio de pesquisa de repertório e seleção de imagens e fenômenos no tema do workshop, realizou três colagens: uma, com imagens referentes aos braços; a segunda, às asas; e, a terceira, às "coisas mecânicas". No período da tarde, as colagens foram expostas, analisadas, debatidas e os alunos iniciaram, então, ainda individualmente, desenhos de estudo à mão livre, sobre papel para aquarela, como ampliações de partes específicas, ou elementos de especial interesse das asas e demais estruturas da natureza, advindas das experiências de colagem.

$\mathrm{Na}$ manhã da quinta-feira, esses desenhos foram desenvolvidos e finalizados. Em seguida, ao longo da tarde, sobre folhas translúcidas de poliéster Mylar, dois outros desenhos foram feitos sobre os primeiros: um desenho como abstração (geometrizando e sintetizando uma composição em foco), e outro desenho como objeto, investigando as possibilidades de construção de um modelo tridimensional, a partir de tais aproximações.

Na sexta-feira, após uma breve apresentação de imagens feita pelo professor Viscardi e da apresentação dos alunos das possibilidades de evolução e transformação percebidas nos desenhos (2D) e nas estruturas físicas (3D), iniciaram-se os trabalhos de modelagem no Lame, individualmente, utilizando-se, como materiais principais, varetas de madeira de seções variadas, tubos e peças de PVC, placas de MDF ou compensado e chapas de acrílico colorido, fosco, transparente e translúcido. O objetivo dessa representação tridimensional era construir manualmente, com o amparo do maquinário convencional, modelos de estudo e simulação das estruturas biológicas escolhidas pelos alunos.

Para a finalização desses modelos e o início do desenvolvimento de modelos análogos, o Lame foi aberto, excepcionalmente, no sábado 11 de fevereiro, e os alunos puderam, então, fazer uso do maquinário, assim como contar com o apoio dos técnicos.

A retomada dos trabalhos na manhã da segunda-feira, 13 de fevereiro, envolveu uma revisão crítica da produção dos padrões "de simulação" e "análogos" realizados, e o início de trabalhos em grupo, duplas ou trios - por afinidades de enfoque e similaridades estruturais -, para a confecção de objetos propositivos, em escala, integrando, à modelagem manual, recursos de modelagem eletrônica com base na máquina de corte a laser.

Ao longo de toda a terça e a quarta-feira, os alunos se dedicaram à execução de seus modelos, realizando um processo formativo, amparado no diálogo entre suportes (materiais diversos) e tecnologias (máquinas, técnicas e procedimentos), e no papel ativo da integração entre diferentes representações bi e tridimensionais. A percepção de o processo de projeto nem sempre ocorrer de forma linear trouxe à 
tona a dialética entre "o pensar e o fazer", vivenciada nessa experiência, no rebatimento da interação modelo/desenho, que demanda ajustes, retornos, verificando os pressupostos sobre o funcionamento de partes, de mecanismos e de escalas de resolução imaginadas nas propostas de projeto.

Na quinta-feira, dia 16 de fevereiro, os modelos foram finalizados, e cada equipe compôs uma prancha-síntese de seu processo. À tarde, no Salão Caramelo, organizou-se uma exposição com os vários modelos e desenhos realizados ao longo de uma semana de trabalho, e iniciou-se um processo de reflexão e debate que contou com as colocações preliminares do professor Viscardi, complementadas depois por apresentações dos alunos participantes e comentários de professores participantes e convidados. Esse encerramento das atividades do workshop, que permitiu uma apreensão geral da produção e dos entendimentos construídos sobre a experiência, contou ainda com a presença de vários alunos da FAU, professores e técnicos dos laboratórios envolvidos.

Esse workshop foi divulgado e debatido também na sede do curso de pósgraduação da FAU, em palestra aberta realizada no dia 27 de fevereiro, como desdobramento e nova oportunidade de reflexão sobre a experiência e o processo projetual vivenciado ao longo desse curso imersivo. Nessa ocasião, foi organizada

uma exposição dos modelos e desenhos, na Sala dos Espelhos, na FAU-Maranhão, seguida de uma palestra de encerramento proferida pelo professor Viscardi, com o título "Design process", na qual, além da apresentação de outras experiências similares, foram também construídas perspectivas críticas sobre o processo e a produção resultante do trabalho coletivo empreendido na FAU.

\section{CONSIDERAÇÕES FINAIS E DESDOBRAMENTOS FUTUROS}

O workshop proporcionou uma situação peculiar de interação entre alunos, professores e técnicos, concentrados no mesmo propósito, compartilhando diariamente a dinâmica de desenvolvimento de colagens, desenhos e modelos tridimensionais, assim como as reflexões quanto à natureza e características dos processos projetuais. Constituiu-se, em suma, em uma ocasião oportuna para a reflexão sobre questões metodológicas, epistemológicas e sistêmicas, os processos de projeto e produção, temas que estão na pauta das discussões na área de concentração em design e arquitetura e suas atuais linhas de pesquisa: "Projeto e linguagem" e "Percepção ambiental, imagem e representação visual", como também na área de concentração de Tecnologia, especialmente na linha de pesquisa "Processo de produção da arquitetura e do urbanismo/representações".

A vivência do workshop, certamente, repercutirá na atividade dos alunos participantes, nas próximas situações de projeto, e será difundido no contato com seus colegas, ganhando novos relevos e apropriações. No caso dos alunos de pósgraduação envolvidos, a possibilidade de vivenciar essa proposta pedagógica e, ao mesmo tempo, refletir sobre metodologias experimentais de projeto, com o foco na inventividade, em associação com ações mentais de ordem perceptiva, constituiu experiência ímpar, podendo se espraiar em suas atividades de pesquisa e ensino. Nas atividades dos docentes, é certo que também haverá ressonâncias, tanto nas reflexões e práticas realizadas em sala de aula quanto nas frentes de pesquisa. Espera-se que o contato com o professor Viscardi e, por extensão, com a Lehigh University, seja fortalecido, consolidando e ampliando a interação entre as duas instituições, ao constituir outras oportunidades de workshops, cursos, pesquisas e 
publicações conjuntas. Cabe dizer, ainda, que a intensa dedicação dos alunos da FAU à proposta de trabalho conduzida pelo professor Viscardi, permitiu que se atingisse, em uma semana, o que costuma levar ao menos o dobro do tempo para se realizar, mantendo um excelente nível de qualidade, tanto na produção quanto na capacidade de reflexão e perspectiva crítica sobre os próprios procedimentos.

A partir dessas colocações, alguns aspectos podem ser pontuados, para reflexão:

- O desenvolvimento de cursos e workshops de verão e inverno, em fevereiro e julho, como atividades extracurriculares, que podem ter caráter de extensão, possui um grande potencial pedagógico e de pesquisa, colabora com o fortalecimento do papel didático dos laboratórios (Lame, LPG, FotoFAU e VideoFAU) e pode ser intensificado na Escola;

- a interação entre alunos de graduação e pós, que se experimentou nesse workshop, mostrou ser extremamente frutífera e desejável, podendo ser retomada em outras ocasiões futuras;

- a relação entre ensino e pesquisa, tendo como aproximação uma atividade prática, constitui estratégia para a promoção de reflexões e debates nas áreas da arquitetura e do design, notadamente nos estudos da pós-graduação;

- em uma perspectiva comparativa com outras experiências, em workshops realizados em outras partes do mundo, chamou a atenção do professor Viscardi a capacidade de nossos alunos para dialogar e trabalhar em grupo, qualidade que, em nosso cotidiano, talvez por um excesso de familiaridade, raramente se reconhece.

Este relato sucinto pretende ser um registro preliminar da atividade desenvolvida, que colabora com a documentação e difusão dessa experiência, e que encontrará, em breve, oportunidade de uma apresentação mais detalhada, em publicações futuras já em andamento.

\section{Agradecimentos}

À Pró-Reitoria de Pós-Graduação da Universidade de São Paulo, à Diretoria da FAU, na pessoa do senhor diretor professor Marcelo de Andrade Roméro, à Comissão de Pós-Graduação da FAUUSP, em especial à sua presidente, professora Maria Lucia Refinetti Rodrigues Martins, a todos os funcionários do Lame, do Laboratório de Fotografia, do Laboratório de Vídeo, do LPG, da Secretaria do Departamento de Projeto e dos setores de Eventos e de Manutenção, ao arquiteto Alexandre Lopes, por seu apoio na montagem da exposição na FAU-Maranhão, e à aluna Tania Mayumi Senaga, pelo apoio à preparação, realização e comunicação referente às atividades do workshop.

\section{Clice de Toledo Sanjar Mazzilli}

Departamento de Projeto aup@usp.br; clice@usp.br (11) 3814-9380

\section{Cibele Haddad Taralli}

Departamento de Projeto aup@usp.br; cibelet@usp.br (11) 3091-4577

Artur Simões Rozestraten

Departamento de Tecnologia da Arquitetura aut@usp.br; artur.rozestraten@usp.br

(11) 3091-4570 